\title{
Phosphatidylserine plasma membrane asymmetry in vivo: a pancellular phenomenon which alters during apoptosis
}

\author{
Stefan M. Van den Eijnde ${ }^{1,5}$, Lenard Boshart ${ }^{1}$, \\ Chris P.M. Reutelingsperger ${ }^{2}$, Chris I. De Zeeuw ${ }^{3}$ and \\ Christl Vermeij-Keers ${ }^{3,4}$ \\ ${ }^{1}$ Department of Cell Biology and Genetics, Institute of Clinical Genetics, \\ Erasmus University Medical School, Rotterdam, The Netherlands \\ 2 Department of Biochemistry, Cardiovascular Research Institute, Limburg State \\ University, The Netherlands \\ ${ }^{3}$ Department of Anatomy, Erasmus University Medical School, Rotterdam, The \\ Netherlands \\ ${ }^{4}$ Department of Plastic and Reconstructive Surgery, Erasmus University \\ Medical School, Rotterdam, The Netherlands \\ ${ }^{5}$ corresponding author: S.M. Van den Eijnde, Department of Cell Biology and \\ Genetics, Institute of Clinical Genetics, Erasmus University Medical School, PO \\ BOX 1738, 3000DR Rotterdam, The Netherlands: tel: +31104087303; \\ fax: +31104365780; email: vandeneijnde@ikg.fgg.eur.nl
}

Received: 20.9.96; revised: 16.12.96; accepted: 21.1.97

Edited by A.H. Wyllie

\begin{abstract}
The distribution of phospholipids across the two leaflets of the plasma membrane is important for many cellular processes including phagocytosis and hemostasis. In the present study we investigated the in vivo plasma membrane distribution of the aminophospholipid phosphatidylserine in mouse embryos with a novel technique employing Annexin $\mathrm{V}, \mathrm{a} \mathrm{Ca}^{2+}$ dependent phosphatidylserine binding protein, conjugated to fluorescein isothiocyanate and biotin. Annexin V directly applied to cryostat sections labeled the plasma membrane of all cells at the interface. In contrast, Annexin V injected intracardially into viable mouse embryos labeled almost exclusively apoptotic cells. These apoptotic cells were visible in all tissues and derived from all germ layers. Our experiments demonstrate that phosphatidylserine is asymmetrically distributed between the two leaflets of the plasma membrane in virtually all cell types in vivo and that this asymmetry is lost early during apoptosis.
\end{abstract}

Keywords: Annexin V, cell death, mouse embryo, phagocytosis, phospholipids

Abbreviations: AnxV, Annexin V; PM, plasma membrane; ABC, ATP-binding cassette; PS, phosphatidylserine; AnxVFITC, Annexin V conjugated to fluorescein isothiocyanate; PC, Post coitum; LM, light microscopical; EM, electron microscopical; PBS, phosphate buffered saline; DAB, 3,3'-diaminobenzidine tetrahydrochloride

\section{Introduction}

In vitro studies mainly of blood cells have shown that the two major classes of the plasma membrane (PM) phospholipids, the choline- and aminophospholipids, are distributed asymmetrically between the two leaflets of the PM. Sphingomyelin and phosphatidylcholine comprise the majority of the outer leaflet while ethanolamine and serine phospholipids reside predominantly in the leaflet facing the cytosol (Devaux, 1991).

The PM transverse translocation of phospholipids is mediated by so-called flippases (Higgins, 1994; Diaz and Schroit, 1996). The first flippase has recently been identified. This phosphatidylcholine translocase is the mdr2 p-glycoprotein gene product (Mdr2) (Smit et al, 1993), which is a member of the phylogenetically old, ATP-binding cassette (ABC) transporter superfamily (Higgins, 1992). In an ATP/ $\mathrm{Mg}^{2+}$ dependent manner, this translocase flips phosphatidylcholine from the cytoplasm-facing leaflet to the opposite orientation (Ruetz and Gros, 1994). A similar machinery seems to regulate the phosphatidylserine (PS) distribution across the PM (Tang et al, 1996). A PS specific energy dependent out-in translocase activity (Martin and Pagano, 1987; Seigneuret and Devaux, 1984; Zachowski et al, 1989) was measured in membranes of anucleated (Seigneuret and Devaux, 1984) and nucleated (Devaux, 1991; Tang et al, 1996) cell types in vitro. For blood platelets it was shown that the PS translocase activity can be enhanced under conditions that give rise to the appearance of PS in the outer leaflet (Tilly et al, 1990). This regulatory mechanism provides a steady state with low levels of surface exposed PS (Diaz and Schroit, 1996).

In vitro studies have also indicated the existence of molecular machineries that counteract the above regulation causing an increase of PS in the outer leaflet of the PM (Diaz and Schroit, 1996). Receptor/ligand activated platelets (Bevers et al, 1983), and ageing erythrocytes (Connor et al, 1994) as well as apoptotic hematopoietic cell lines (Fadok et al, 1992a; Martin et al, 1995; Vermes et al, 1995) express PS at their cell surface while keeping PM integrity intact. The surface exposed PS catalyses reactions of the coagulation system (Bevers et al, 1982) and mediates recognition and uptake by phagocytes (Connor et al, 1994; Fadok et al, 1992a, b). Receptor/ligand activated platelets exhibit a scramblase activity with concomitant inhibition of the PS translocase and redistribute PS symmetrically over the two leaflets of the PM (Williamson et al, 1995). Both the translocase and scramblase activity are regulated by cytosolic $\mathrm{Ca}^{2+}$ levels (Williamson et al, 1995). Nucleated cells regulate PS asymmetry of the PM similar to platelets. During apoptosis of lymphocytes in vitro PS translocase is inhibited and the scramblase is activated (Verhoven et al, 1995). Recently the scramblase present in erythrocytes has been isolated and purified (Basse et al, 1996).

In the present study we have assessed the PS asymmetry of the PM in vivo in whole mouse embryos utilizing Annexin V. This protein is a member of the Annexin family of structural and functional related proteins (Van Heerde et al, 1995) and engages specifically with PS in a calcium-dependent manner through a putative binding 
pocket for the serine headgroup (Swairjo et al, 1995). The presence of PS in cells was monitored by applying Annexin $\mathrm{V}$ conjugated to fluorescein isothiocyanate (AnxV-FITC) directly to cryostat sections of mouse embryos. The presence and extent of PS at the outer PM leaflet was assessed by intracardiac injection of biotinylated Annexin $V$ (AnxV-biotin) into viable mouse embryos.

\section{Results}

\section{All cells with exposed interior bind Annexin V}

Applying AnxV-FITC to cryostat sections through limbs of day 13 mouse embryos showed that all cells contain Annexin $\mathrm{V}$ binding sites (Figure 1). The PM was especially intensely labeled. To a lesser degree, labeling was also observed at the nuclear membrane.

\section{Distribution of intracardially administered Annexin V}

AnxV-biotin was injected intracardially in vital mouse embryos such that the entire circulatory system was thoroughly perfused and widespread interstitial distribution was achieved. AnxV-biotin and heat inactivated AnxV-biotin, (i.e. AnxV-biotin with a destroyed phospholipid binding activity; Reutelingsperger et al, 1985), were administered to embryos of 11,12 and 13 days post coitum (PC). While embryos injected with heat inactivated AnxV-biotin did not show any cell labeling, those that were injected with active AnxV-biotin showed cell labeling at specific locations in the whole organism (Figure 2).

Cells derived from all three germ layers were labeled at the many sites where cell death appears during morphogenesis (Glücksmann, 1951). Depending on embryonic age, AnxV-biotin binding was present with left-right symmetry and cranially in the more differentiated organs (Poelmann and Vermeij-Keers, 1976), e.g. eye (Figure 2a), in both the soma and axons of neurons of the central (Figure 2a, b) and peripheral (Figure 2c) nervous system, bronchi (Figure 2d), and caudally in primitive organs, e.g. somites and degenerating tailgut (Figure 2e) (Nievelstein et al, 1993). In addition, many labeled cells were observed in the degenerating interdigital tissue (Figure 2f).

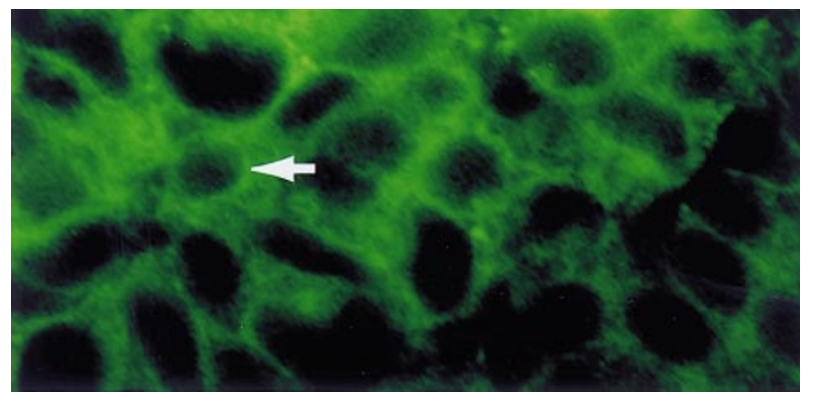

Figure 1 Cryostat section through day 13 mouse embryo limb, showing Annexin V binding sites in cells with exposed interior. AnxV-FITC binding was present in all cells, both at the nuclear membrane and PM (arrow).

\section{Apoptotic cells bind Annexin V}

The above results indicate that Annexin $\mathrm{V}$ binding cells are located in regions where cell death occurs during morphogenesis. To verify whether these cells were apoptotic, labeled cells in the interdigital mesenchymal tissue of day 13 mouse embryos were investigated for their ultrastructural characteristics.

AnxV-biotin positive cells showed the ultrastructural characteristics of apoptosis (Wyllie et al, 1980). Throughout the sections examples were found of AnxV-biotin labeled cells, undergoing phagocytosis including engulfment by neighboring cells, and more advanced stages of intraphagolysosomal degradation (Figure $3 a$ and b). Other positive cells had more condensed chromatin (Figure $3 c$ and d) and loss of electron density of the cytoplasm which contained an increased proportion of free ribosomes and dilated endoplasmatic reticulum while other organelles appeared unchanged (Figure 3c). The AnxV-biotin binding cells in later stages of apoptosis showed advanced chromatin condensation (Figure 3e), nuclear pyknosis (Figure 3f), and cell fragmentation.

\section{Exceptions}

In all the cases the Annexin $\mathrm{V}$ binding cells showed the morphology of apoptosis. However, two evidently nonapoptotic cell types also appeared to bind AnxV-biotin at their PM: (i) myoblasts differentiating into myotubes composed of a sarcolemma that closely ensheaths several aligned nuclei (Figure 4a) and myocardioblasts forming cardiac muscle (data not shown), and (ii) megakaryoblast and megakaryocytes in the liver, recognisable for their large size, polymorphic nucleus and the many thrombocyte-like attachments (Figure 4b).

\section{Discussion}

This paper demonstrates that regulation of PS topography and, consequently asymmetric membrane architecture, is a ubiquitous process during morphogenesis. All cell types confine PS to the cytoplasm-facing leaflets when viable. The process of apoptotic cell death results in PS exposure at the outer leaflet of the PM.

Annexin $\mathrm{V}$ is a protein that strongly binds to PScontaining membranes in the presence of $\mathrm{Ca}^{2+}$ (Van Heerde et al, 1995). Utilizing this capacity, in vitro studies indicated that Annexin V specifically marks apoptotic human neutrophils (Homburg et al, 1995), germinal Blymphocytes (Koopman et al, 1994) and peripheral blood lymphocytes (Vermes et al, 1995). A study with hematopoietic cell lines and Annexin $\mathrm{V}$ demonstrated that these cells expose PS at the cell surface during apoptosis in culture, from an early stage onwards and regardless of the initiating stimulus (Martin et al, 1995).

We have applied Annexin $V$ to study loss of PM asymmetry in vivo. Mouse embryos were used as a model, because they carry spontaneous, spatiotemporally consistent cell death patterns (Glücksmann, 1951). While all cells possess Annexin $\mathrm{V}$ binding sites, as we 
demonstrated by cryostat sections, perfusion of viable embryos with AnxV-biotin revealed that only specific cell populations bear these binding sites at their cell surface. The interaction of AnxV-biotin with the embryonic cells relies on its phospholipid binding property, as was shown from our control experiment with heat inactivated AnxVbiotin.

Active AnxV-biotin identified cells at locations where cell death serves morphogenesis; in cells derived from all three germlayers, and both in primitive (Nievelstein et al, 1993; Vermeij-Keers and Poelmann, 1980) and in more differentiated tissues (Glücksmann, 1951; Poelmann and Vermeij-Keers, 1976). The whole cells were labeled, which was best visualized in dying neurons, with their labeling of both the soma and axons. At both the light microscopical (LM) and electron microscopical (EM) level, the AnxV-biotin labeled cells fitted into the sequence of morphological stages that apoptotic cells undergo (Poelmann and Vermeij-Keers, 1976; Wyllie, 1992; Wyllie et al, 1980), from the earliest stages, hardly distinguishable from viable neighboring cells, up to intraphagolysosomal degradation.

The consistent presence of PS on the outer layer of the PM of apoptotic cells and the common absence of PS exposure by viable cells suggests a tight regulation of PS PM asymmetry. This predicts an important physiological role for this process in vivo. One such a role may exist in the process of phagocytosis. It is this process that largely determines the elimination of apoptotic cells without any inflammatory reaction (Kerr et al, 1972; Martin et al, 1994; Savill et al, 1993). In effecting this, apoptotic cells must be recognized and ingested rapidly by phagocytes before membrane integrity is lost and the cells eventually succumb
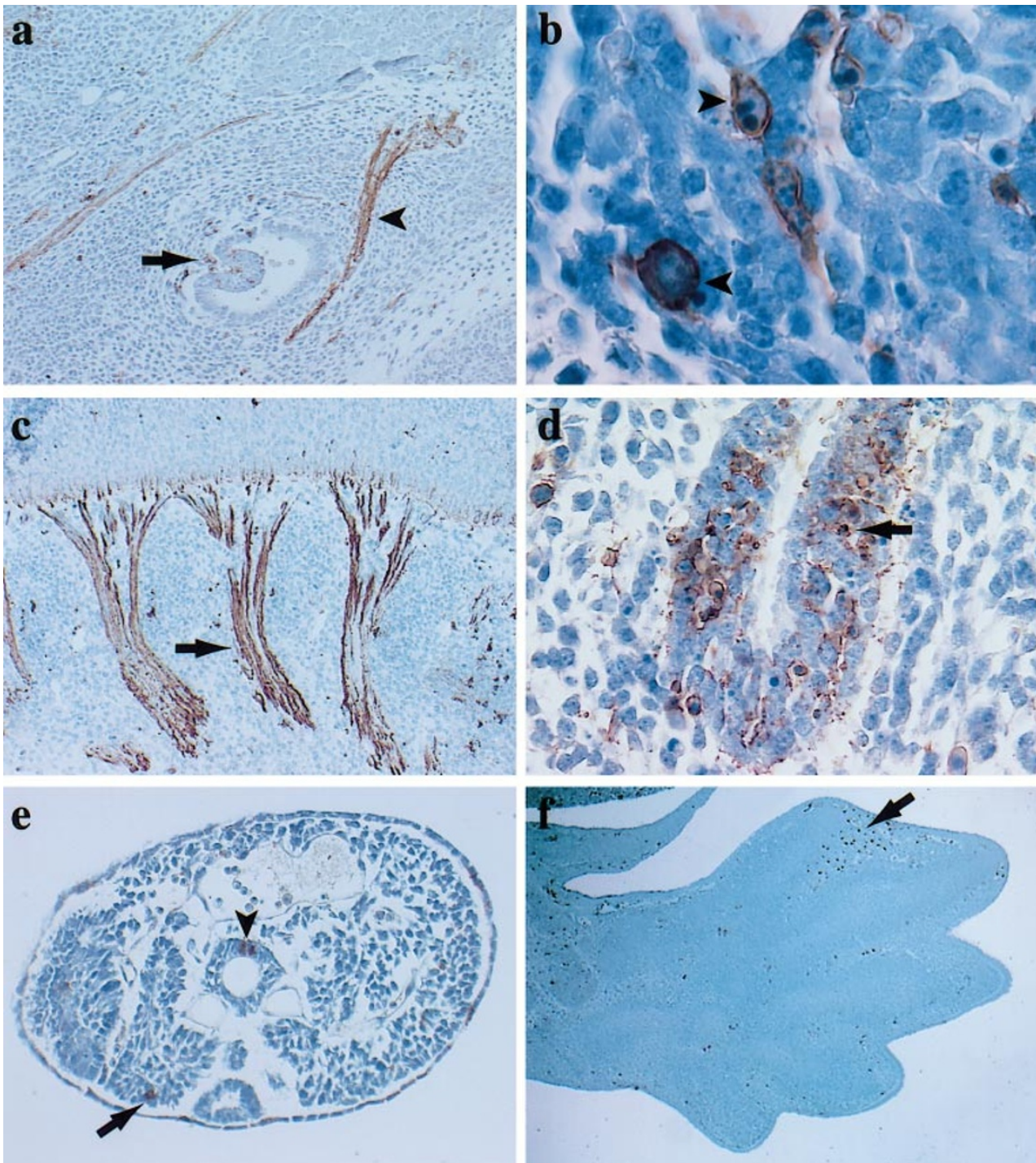

Figure 2 Examples of AnxV-biotin labeling in day $11(\mathbf{a}, \mathbf{b}, \mathbf{d}, \mathbf{e})$, day 12 (c) and day 13 (f) mouse embryos: eye (a: arrow), both the soma and axons of neurons of the central (a, b: arrowhead) and peripheral (c: arrow) nervous system, bronchi (d: arrow), somites (e: arrow) and degenerating tailgut (e: arrowhead). In between digits also the cells were marked (f: arrow). 
to lysis (Majno and Joris, 1995; Wyllie, 1992). Exposure of PS after loss of PM asymmetry is one of three general structural changes in the PM of apoptotic neutrophils and lymphocytes that have been identified in vitro, together with formation of thrombospondin binding sites, and exposure of side chain sugars after loss of sialic acid (Savill et al, 1993). Like in the latter two, PS exposure may well permit
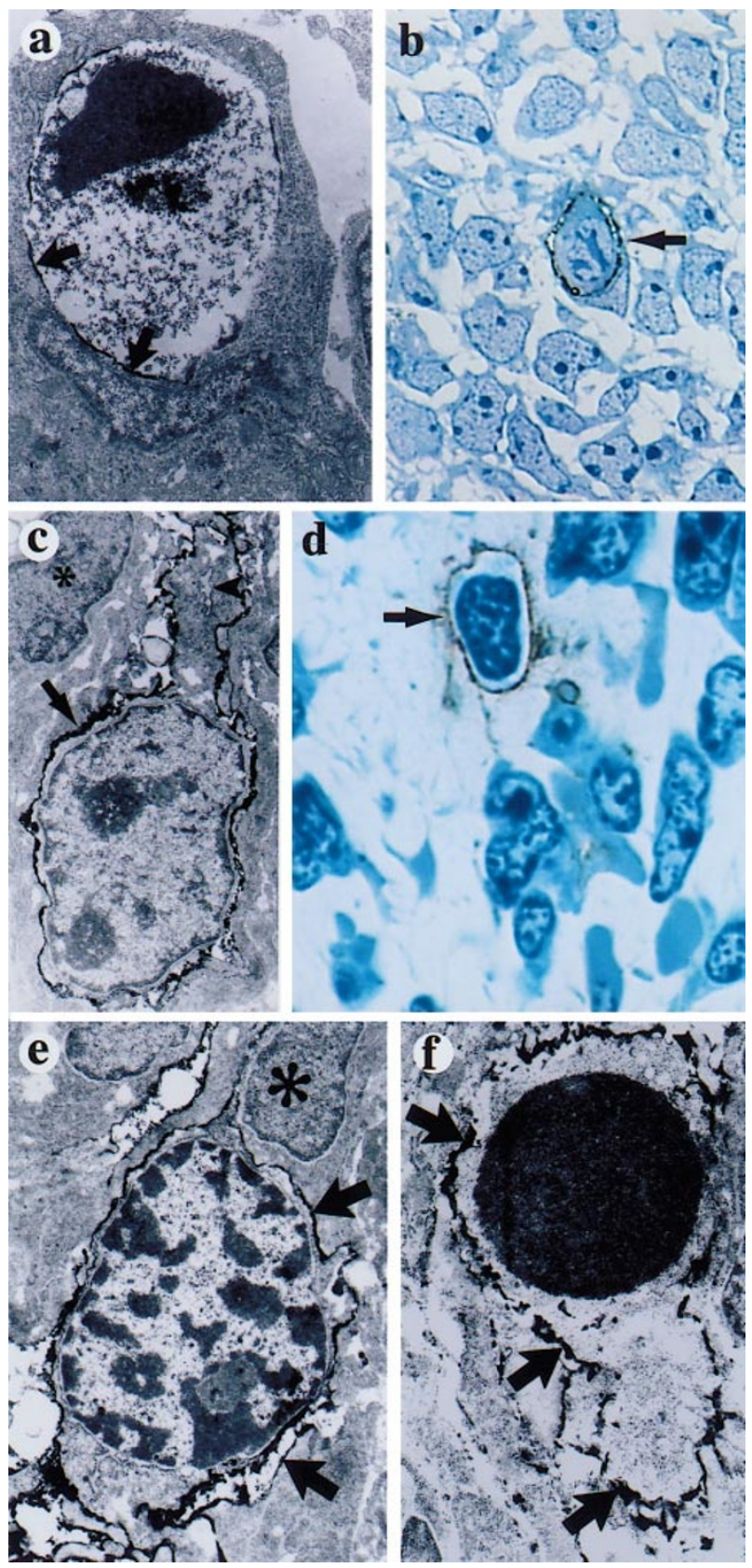

Figure 3 AnxV-biotin labeled cells (arrows) in day 13 mouse embryo interdigital mesenchyme in successive stages of apoptosis (EM: a, c, e, f; LM: b, d): ingested by phagocytes (a, b); early apoptotic, showing loss of electron density of the protoplasm, a dilated endoplasmatic reticulum (c: arrowhead; viable cell: asterix) and starting chromatin condensation (c, d); with advanced chromatin condensation (e) pyknotic, c.q. late apoptotic cell (f). recognition by phagocytes, which remove the dying cell by phagocytosis.

From our study it appears that the presence of PS at the outer PM marks the entire period of cell progression through apoptosis from the earliest stages, hardly distinguishable from viable cells, up to intraphagolysosomal degradation. The involvement of PS in phagocytosis of apoptotic cells may then explain why in in vitro phagocytic assays, next to phagocytes containing recognizable apoptotic cells, phagocytes have also been observed containing apparently viable cells (Savill et al, 1989). Moreover, it also explains the clearance of apoptotic cell fragments during morphogenesis. These cell fragments too still bear the surface structures necessary for recognition and removal by phagocytes.

In addition to apoptotic cells, two types of viable cells were observed to express Annexin V-binding sites at their cell surface. This may reflect a PS-dependent pathway for intercellular recognition shared by apoptotic cells and invoked by viable cells under specific conditions. The AnxV-biotin positive myoblast must promote homotypic recognition to fuse into myotubes and heart muscle syncytium. The AnxV-biotin positive megakaryocytes and megakaryoblasts may invoke the PS-dependent recognition pathway to keep the entities of already distinguishable platelet structure together until maturation is completed and platelets are dispersed. Within this concept of intercellular recognition an independently regulated but associated mechanism of phagocytosis should be considered. Whereas the apoptotic cells drive phagocytes to phagocytose them, myoblasts, megakaryocytes and megakaryoblasts should be inert in this respect or even discourage phagocytes to approach and phagocytose. Involvement of PS exposure in attachment of cells to each other without ending up in phagocytosis may indeed take place in certain circumstances, such as was observed in recent studies on the scavenger receptor present on mouse peritoneal macrophages. These macrophages bind erythrocytes exposing PS without subsequent engulfment (Ottnad et al, 1995; Sambrano and Steinberg, 1995).

In conclusion, our results indicate that confinement of PS to the inner leaflet of the PM is a ubiquitous process of
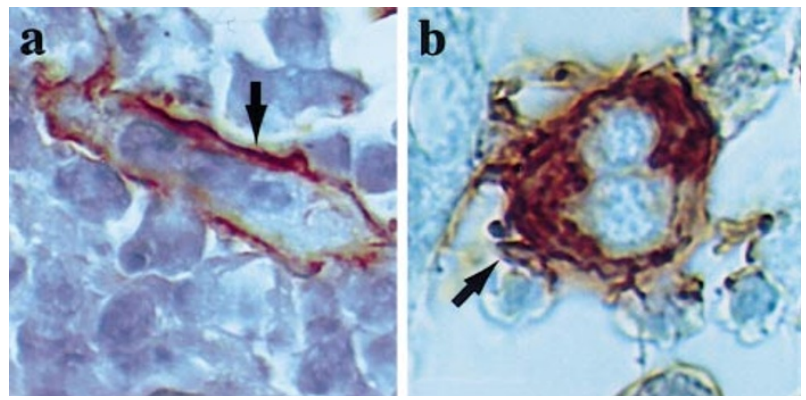

Figure 4 Annexin V labeled non-apoptotic cells (arrows) in paraffin embedded serially sectioned mouse embryos. (a) Section through a day 12 embryo showing membrane labeling of a myotube. (b) Section through a day 13 embryo showing a membrane labeled megakaryocyte. 
viable cells in vivo. This PS PM asymmetry changes in surface exposure of PS early during apoptosis, irrespective from which germ layer the cells are derived. The general commitment of cells to this concept of regulation of PS PM topography makes it possible to visualize the many sites of apoptosis that are present during embryogenesis in situ, both at the topographical and at the ultrastructural level.

\section{Materials and Methods}

\section{Experimental animals}

Eighteen pregnant FVB-mice, from 11-13 days PC (plug=day 0), were killed by cervical dislocation after ether anesthesia. The uteri were dissected out and from the embryos collected, 116 were used for this study. From these embryos; nine were directly processed for cryostat sectioning and 107 were temporarily cultured for control experiments using heat inactivated AnxV-biotin $(n=16)$ and for detection of loss of PS asymmetry of the PM by microinjection of AnxV-biotin (LM, $n=54$; EM, $n=37$ ).

\section{Binding of FITC conjugated Annexin V to cryostat sectioned embryos}

Day 13 mouse embryo limbs were sectioned on a cryostat (CM3000, Reichert Jung, Germany) at $10 \mu \mathrm{m}$. Directly thereafter, sections were washed with HEPES buffer, incubated for one minute with AnxV-FITC (APOPTEST ${ }^{\mathrm{TM}}$-FITC kit, a product from NeXins Research BV, The Netherlands), washed again with HEPES buffer and mounted with anti fading agent. The slides were stored at $-4^{\circ} \mathrm{C}$ until examination. Sections were examined under a microscope using standard settings for FITC fluorescence-detection.

\section{Heat inactivated Annexin V-biotin}

AnxV-biotin was inactivated by heating it for $10 \mathrm{~min}$ at $56^{\circ} \mathrm{C}$ (Reutelingsperger et al, 1985). Microinjection and staining procedures were identical to those used for active Annexin V-biotin. Non-specific binding of Annexin $V$ and quenching of endogenous peroxidase activity was tested for in this manner.

\section{Microinjection of Annexin V-biotin}

Embryos were perfused by microinjection using a Hamilton-Syringe pipetting system with glass needles (tip diameter $\sim 20 \mu \mathrm{m}$ ). Per embryo, a volume of approximately $3 \mu \mathrm{l} \mathrm{AnxV-biotin}(660 \mu \mathrm{g} / \mathrm{ml})$, purchased from NeXins Research BV, The Netherlands, (APOPTEST $^{\mathrm{TM}}$-biotin kit), was injected through the ventricle of the heart under a surgical microscope while the embryo was kept in HEPES buffer (20 mM HEPES (pH 7.4), $132 \mathrm{mM} \mathrm{NaCl}, 2.5 \mathrm{mM} \mathrm{CaCl}_{2}, 6 \mathrm{mM}$ $\mathrm{KCl}, 1 \mathrm{mM} \mathrm{MgSO}_{4}, 1.2 \mathrm{mM} \mathrm{K}_{2} \mathrm{HPO}_{4}, 5.5 \mathrm{mM}$ glucose, 0.5\% BSA) at $37^{\circ} \mathrm{C}$. When injected, a temporary blanching of the umbilical vein could be seen. Successfully injected embryos that showed heart activity after 30 min of incubation were fixed overnight in HEPES buffer containing $4 \%$ formalin at $4{ }^{\circ} \mathrm{C}$ and further processed for $L M$.

\section{Detection of Annexin V binding-biotin, LM}

Following fixation embryos were dehydrated, embedded in paraffin and serially sectioned at $3 \mu \mathrm{m}$. Endogenous peroxidase activity was blocked by incubation in methanol/ $\mathrm{H}_{2} \mathrm{O}_{2}(9: 1 \mathrm{v} / \mathrm{v})$ for $20 \mathrm{~min}$. Sections were washed in phosphate buffered saline (PBS). Bound AnxV-biotin was visualized using the avidin-biotin complex method with horseradish peroxidase conjugated avidin ( $A B C$ Elite kit, Vector Laboratories, USA) at room temperature. After washing with PBS, staining was developed with $3,3^{\prime}$-diaminobenzidine tetrahydrochloride (DAB) $(0.05 \%)$, and counterstained with Hematoxylin.

\section{Detection of Annexin V-biotin binding, EM}

Day 13 embryos were processed for EM. The embryos were dissected out of the uterus, microinjected with Annexin $V$ as described above, and subsequently intracardially perfused with $0.5 \mathrm{ml} 2 \%$ glutaraldehyde and $2 \%$ paraformaldehyde in $0.1 \mathrm{M}$ cacodylate buffer. The limbs were removed, postfixed overnight in the same fixative, and cut on a Vibratome into $50 \mu \mathrm{m}$ sections, which were processed to visualize the biotinylated Annexin $\mathrm{V}$ as described for $\mathrm{LM}$. After the reaction with $\mathrm{DAB}$, the sections were postfixed in $1.5 \% \mathrm{OsO}_{4}$ in a $8 \%$ glucose solution, rinsed in aquadest, stained en bloc in 3\% uranyl acetate, dehydrated in dimethoxypropane and embedded in Durcupan (for details of EM procedures see: De Zeeuw et al, 1988, 1989). Semithin and ultrathin tissue sections were cut on an ultratome (Ultracut S, Reichert Jung, Germany); semithin and ultrathin sections were counterstained with Toluidine blue and with lead citrate, respectively. The ultrathin sections were examined in a Philips electron microscope (CM 10).

\section{Acknowledgements}

The financial support by the Rotterdam Foundation of Clinical Genetics (SvdE, LB) is gratefully acknowledged. We would like to thank Dr Eduard Bevers for critically reading the manuscript and helpful suggestions. We are grateful to Mr Cor van Vroonhoven for technical suggestions and helping us in fine tuning our protocols. We thank Mrs Cecile Maassen, $\mathrm{Mr}$ Richard Hawkins and Mr Hans van der Burg for their skilful technical assistance and $\mathrm{Mr}$ Tom de Vries-Lentsch and $\mathrm{Mr} \mathrm{Ed}$ Dalm for photography.

\section{References}

Basse F, Stout JG, Sims PJ and Wiedmer T (1996) Isolation of an erythrocyte membrane protein that mediates $\mathrm{Ca}^{2+}$-dependent transbilayer movement of phospholipid. J Biol Chem 271: 17205-17210

Bevers EM, Comfurius P, Van Rijn JLML, Hemker HC and Zwaal RFA (1982) Generation of prothrombin-converting activity and the exposure of phosphatidylserine at the outer surface of platelets. Eur J Biochem 122: 429-436

Bevers EM, Comfurius P and Zwaal RFA (1983) Changes in membrane phospholipid distribution during platelet actiation. Biochim Biophys Acta 736: 57-66

Connor J, Pak CH and Schroit AJ (1994) Exposure of phosphatidylserine in the outer leaflet of human red cells. Relationship to cell density, cell age and clearance by mononuclear cells. J Biol Chem 269: 2399-2404

De Zeeuw Cl, Holstege JC, Calkoen F, Ruigrok TJH and Voogd J (1988) A new combination of WGA-HRP anterograde tracing and GABA-immunocytochemistry applied to afferents of the cat inferior olive at the ultrastructural level. Brain Res 447: 369-375

De Zeeuw Cl, Holstege JC, Ruigrok TJH and Voogd J (1989) An ultrastructural study of the GABAergic, the cerebellar and the mesodiencephalic innervation of the cat medial accessory olive: anterograde tracing combined with immunocytochemistry. J Comp Neurol 284: 12-35

Devaux PF (1991) Static and dynamic lipid asymmetry in cell membranes. Biochemistry 30: 1163-1173

Diaz C and Schroit AJ (1996) Role of translocases in the generation of phosphatidylserine asymmetry. J Membrane Biol 151: 1-9

Fadok VA, Savill JS, Haslett C, Bratton DL, Doherty DE, Campbell PA and Henson PM (1992a) Different populations of macrophages use either the vitronectin receptor or the phosphatidylserine receptor to recognize and remove apoptotic cells. J Immunol 149: 4029-4035 
Fadok VA, Voelker DR, Campbell PA, Cohen JJ, Bratton DL and Henson PM (1992b) Exposure of phosphatidylserine on the surface of apoptotic lymphocytes triggers specific recognition and removal by macrophages. J Immunol 148: 2207-2216

Glücksmann A (1951) Cell deaths in normal vertebrate ontogeny. Biol Rev Camb Philos Soc 26: 59-86

Higgins CF (1992) ABC transporters: from microorganisms to man. Ann Rev Cell Biol 8: $67-113$

Higgins CF (1994) Flip-flop: the transmembrane translocation of lipids. Cell 79:393395

Homburg CHE, DeHaas M, Von Dem Borne AEGK, Verhoeven AJ, Reutelingsperger CPM and Roos D (1995) Human neutrophils lose their surface Fc $\gamma$ RIII and acquire Annexin $\mathrm{V}$ binding sites during apoptosis in vitro. Blood 85: 532-540

Kerr JFR, Wyllie AH and Currie AR (1972) Apoptosis: a basic biological phenomenon with wide-ranging implications in tissue kinetics. Br J Cancer 26: 239-257

Koopman G, Reutelingsperger CPM, Kuijten GAM, Keehnen RMJ, Pals ST and Van Oers MHJ (1994) Annexin V for flow cytometric detection of phosphatidylserine expression on B-cells undergoing apoptosis. Blood 84: 1415-1420

Majno $G$ and Joris I (1995) Apoptosis, oncosis, and necrosis. An overview of cell death. Am J Pathol 146: 3-15

Martin OC and Pagano RE (1987) Transbilayer movement of fluorescent analogs of phosphatidylserine and phosphatidylethanolamine at the plasma membrane of cultured cells. Evidence for a protein-mediated and ATP-dependent process(es). J Biol Chem 262: 5890-5898

Martin SJ, Green DR and Cotter TG (1994) Dicing with death: dissecting the components of the apoptosis machinery. TIBS 19: 26-30

Martin SJ, Reutelingsperger CPM, McGahon AJ, Rader J, Van Schie RCAA, LaFace DM and Green DR (1995) Early redistribution of plasma membrane phosphatidylserine is a general feature of apoptosis regardless of the initiating stimulus: inhibition by overexpression of Bcl-2 and abl. J Exp Med 182: 15451556

Nievelstein RAJ, Hartwig NG, Vermeij-Keers C and Valk J (1993) Embryonic development of the mammalian caudal neural tube. Teratology 48: 21-31

Ottnad E, Parthasarathy S, Sambrano GR, Ramprasad MP, Quehenberger O, Kondratenko N, Green S and Steinberg D (1995) A macrophage receptor for oxidized low density lipoprotein distinct from the receptor for acetyl low density lipoprotein: partial purification and role in recognition of oxidatively damaged cells. Proc Natl Acad Sci USA 92: 1391-1395

Poelmann RE and Vermeij-Keers C (1976) Cell degeneration in the mouse embryo: a prerequisite for normal development. In Progress in differentiation research, In Müller-Bérat N, ed. (Amsterdam: North-Holland Publishing Co.) pp. 93-102

Reutelingsperger CPM, Hornstra G and Hemker HC (1985) Isolation and partial purification of a novel anticoagulant from arteries of human umbilical cord. Eur $\mathrm{J}$ Biochem 151: $625-629$

Ruetz S and Gros P (1994) Phosphatidylcholine translocase: a physiological role for the mdr2 gene. Cell 77: 1071-1081

Sambrano GR and Steinberg D (1995) Recognition of oxidatively damaged and apoptotic cells by an oxidized low density lipoprotein receptor on mouse peritoneal macrophages: role of membrane phosphatidylserine. Proc Natl Acad Sci USA 92: $1396-1400$
Savill J, Fadok V, Henson P and Haslett C (1993) Phagocyte recognition of cells undergoing apoptosis. Immunol Today 14: 131-136

Savill JS, Wyllie AH, Henson JE, Walport MJ, Henson PM and Haslett C (1989) Macrophage phagocytosis of ageing neutrophils in inflammation. J Clin Invest 83: $865-875$

SeigneuretMandDevauxPF (1984) ATP-dependent asymmetric distribution of spinlabeled phospholipids in the erythrocyte membrane: relation to shape changes. Proc Natl Acad Sci USA 81: $3751-3755$

Smit JJM, Schinkel AH, Oude Elferink RPJ, Groen AK, Wagenaar E, Van Deemter L, Mol CAA, Ottenhof R, Van der Lugt NMT, Van Roon MA, Van der Valk MA, Offerhaus GJA, Berns AJM and Borst P (1993) Homozygous disruption of the murine mdr2 P-glycoprotein gene leads to a complete absence of phospholipid from bile and to liver disease. Cell 75: 451-462

Swairjo MA, Concha NO, Kaetzel MA, Dedman JR and Seaton BA (1995) $\mathrm{Ca}^{2+}$. bridging mechanism and phospholipid head group recognition in the membranebinding protein Annexin V. Nature Struct Biol 2, 968-974

Tang XJ, Halleck MS, Schlegel RA and Williamson P (1996) A subfamily of P-type ATPases with aminophospholipid transporting activity. Science 272: 14951597

Tilly RH, Senden JMG, Comfurius P, Bevers EM and Zwaal RFA (1990) Increased aminophospholipid translocase activity in human platelets during secretion. Biochem Biophys Acta 1029: 188-190

Van Heerde WL, De Groot PG and Reutelingsperger CPM (1995). The complexity of the phospholipid binding protein annexin V. Thromb Haemost 73: 172-179

Verhoven B, Schlegel RA and Williamson P (1995) Mechanisms of phosphatidylserine exposure, a phagocyte recognition signal, on apoptotic T lymfocytes. J Exp Med 182: 1597-1601

Vermeij-Keers C and Poelmann RE (1980) The neural crest: a study on cell degeneration and the improbability of cell migration in mouse embryos. Neth $\mathrm{J}$ Zool 30: 74-81

Vermes I, Haanen C, Steffens-Nakken H and Reutelingsperger CPM (1995) A novel assay for apoptosis. Flow cytometric detection of phosphatidylserine expression on early apoptotic cells using fluorescein labelled Annexin V. J Immunol Methods 184: $39-52$

Williamson P, Bevers EM, Smeets EF, Comfurius P, Schlegel RA and Zwaal RFA (1995) Continuous analysis of the mechanism of activated transbilayer lipid movements in platelets. Biochemistry 34: 10448-10455

Wyllie AH (1992) Apoptosis and the regulation of cell numbers in normal and neoplastic tissues: an overview. Cancer Metastasis Rev 11: 95-103

Wyllie AH, Kerr JFR and Currie AR (1980) Cell death: the significance of apoptosis. Int Rev Cytol 68: 251-306

Zachowski A, Henry J-P and Devaux PF (1989) Control of transmembrane lipid asymmetry in chromaffin granules by an ATP-dependent protein. Nature 340 : $75-76$ 